\title{
A Biomechanical Finite Element Study of Subsidence and Migration Tendencies in Stand-Alone Fusion Procedures - Comparison of an In Situ Expandable Device with a Rigid Device
}

\author{
Kiapour A ${ }^{1}$, Kiapour AM${ }^{1}$, Kodigudla $\mathbf{M}^{1}$, Hill GM${ }^{2}$, Mishra $\mathrm{S}^{2}$ and Goel VK ${ }^{1 *}$
}

${ }^{1}$ Engineering Center for Orthopedic Research Excellence (E-CORE) 5046 NI, College of Engineering, University of Toledo, Toledo, OH43606, USA ${ }^{2}$ Wenzel Spine, Inc., 206 Wild Basin Drive, Austin, TX, USA

\begin{abstract}
Study Design: Biomechanical study using a finite element model of the lumbar functional spinal unit (FSU).

Objectives: To compare the biomechanics of a novel in situ expandable posterior lumbar interbody fusion (PLIF) device, with a traditional rigid cage used in a stand-alone fashion.

Methods: An experimentally validated intact finite element (FE) model of the L4-L5 FSU was altered to model expandable VariLift-L and BAK devices in a stand-alone fashion. A follower compressive pre-load of $400 \mathrm{~N}$ plus 8.0 Nm of flexion, extension, lateral bending, and axial rotation moments were applied to the model to simulate the physiological loadings. The kinematics and load sharing among various models were compared.

Results: Range of motion analyses showed that fusion utilizing VariLift-L expandable stand-alone device was more effective in limiting motion of the spinal column than the BAK device. The normal load at the device/endplate interface for the VariLift-L was similar to that of the BAK in all loading modes. The A-P shear load for the stand-alone VariLift-L model was higher than the BAK model under flexion.

Conclusions: Due to predicted forces along the A-P direction, axial contact loads in flexion and extension, the lordotic slope of the device and the presence of intact annulus in the anterior region of the disc, the tendency of the VariLift-L device to migrate into the canal and subside into the endplate may be lower, despite the higher A-P shear force predicted for the VariLift- $L$ device. This shape and lordotic expandability act to resist A-P shear forces in the flexion mode. The expandable device has the advantage of adjusting its outer profile to the lordotic angle of the treated segment, ensuring a better contact between the device and endplates. Biomechanically, the VariLift-L interbody fusion device is a good solution for fusion surgery of the lumbar spine segment.
\end{abstract}

Keywords: Interbody expandable device; Lumbar spine; Finite element modeling; Biomechanics

\section{Introduction}

Spinal fusion has long been considered the gold standard for treatment of various spinal disorders [1-5]. The PLIF approach, popularized by Cloward, involves the insertion of bone graft filled devices in the disc space with or without posterior instrumentation [6]. This combination is intended to restore and maintain spinal alignment and stabilize the involved segment, thereby enhancing the fusion process [1-8]. The main purpose of interbody fusion devices is to account for the mechanical deformity due to disc degeneration and provide both mechanical stability to the anterior column and favorable bio-environment promoting successful arthrodesis.

In PLIF, the placement of bilateral devices entails decompression of spinal elements through dissection of part of the disc and other posterior elements [3]. The vertebrae are distracted to stretch the annulus before inserting devices which provides initial stability $[2,3]$. Once the devices are inserted, the tension in the annulus is maintained by the resistance provided by the implants. These devices can vary in both shape and material with the most common options being cylindrical or rectangular devices made of a titanium alloy or poly ether ether ketone (PEEK) [7]. Initially successful, interbody devices were intended to provide weight bearing capabilities at the anterior column to restore or maintain disc height; these devices resulted in mixed clinical success. Subsidence, migration, and difficulty in assessing boney fusion, particularly in threaded titanium devices, were among the most frequently reported problems with these devices. More recently, expandable implant have been developed to overcome the potential disadvantages associated with rigid cages [1]. One example of such a device, the VariLift-L (Wenzel Spine, Inc., Austin, TX), is shown in Figure 1. Expandable devices can be inserted with smaller excision of posterior elements, help maintain lordosis, and allow controlled restoration of disc height/annulus stretching with minimal retraction of neural structures [2]. Novel to the VariLift-L device, the in situ expandability creates a wedge shape, which is intended to provide a relatively large endplate-device contact area for the rigid device surfaces to engage and resist subsidence and migration.

The use of a traditional cage without supplemental fixation has been shown to have mixed clinical successes and a fair measure of controversy [9-11]. Problems associated with traditional cylindrical fusion devices include: subsidence into the vertebral body due to compromised endplates [11-13], anterior or posterior migration [1115], lack of immediate stability which often leads to pseudoarthrosis, extended retraction of the nerve root which can lead to endoneural fibrous, and chronic radiculopathy. Further stabilization with the

*Corresponding author: : Dr. Vijay K. Goel, Distinguished University Professor, Endowed Chair \& McMaster-Gardner Professor of Orthopedic Bioengineering CoDirector, Engineering Center for Orthopedic Research Excellence (E-CORE) 5046 $\mathrm{NI}$, College of Engineering, University of Toledo, Toledo, OH43606, USA, Tel: 419 530-8035; Fax: 419-530-8076; E-mail: Vijay.Goel@utoledo.edu

Received May 21, 2012; Accepted July 14, 2012; Published July 16, 2012

Citation: Kiapour A, Kiapour AM, Kodigudla M, Hill GM, Mishra S, et al. (2012) A Biomechanical Finite Element Study of Subsidence and Migration Tendencies in Stand-Alone Fusion Procedures - Comparison of an In Situ Expandable Device with a Rigid Device. J Spine 1:120. doi:10.4172/2165-7939.1000120

Copyright: $\odot 2012$ Kiapour A, et al. This is an open-access article distributed under the terms of the Creative Commons Attribution License, which permits unrestricted use, distribution, and reproduction in any medium, provided the original author and source are credited. 
Citation: Kiapour A, Kiapour AM, Kodigudla M, Hill GM, Mishra S, et al. (2012) A Biomechanical Finite Element Study of Subsidence and Migration Tendencies in Stand-Alone Fusion Procedures - Comparison of an In Situ Expandable Device with a Rigid Device. J Spine 1:120. doi:10.4172/2165-7939.1000120

Page 2 of 5

addition of posterior instrumentation has led to better clinical outcomes although the disruption of posterior musculature may be related to an increase in postoperative morbidity [16].

The objective of this study was to evaluate the biomechanics of a novel expandable interbody device design, VariLift-L, using an experimentally validated L4-L5 FSU finite element model and to compare it with the BAK cage (Zimmer Spine, Edina, MN) under stand-alone conditions. Our hypotheses are that (1) the in situ lordatic expandable device provides stability similar to the non-expandable cages and (2) will have a reduced tendency to subside and migrate, especially in stand-alone applications.

\section{Materials and Methods}

A ligamentous finite element (FE) model of the L4-L5 FSU, extracted from an experimentally validated model of L3-S1 spine developed by Engineering Center for Orthopedic Research Excellence, was used. This model has been previously used to investigate a number of clinically relevant issues and the model validation has been well documented in these complications studies [17-19]. A brief description of the model and its adaptation for the present study are outlined below.

The model geometry was obtained from CT scans (transverse slices $1.5-\mathrm{mm}$ thick) of a normal cadaveric L3-S1 lumbar segment. The transverse images were transferred into Image J (NIH Bethesda, $\mathrm{MD)}$ software to create a cloud of nodes representing the geometry of the model. Abaqus (Simulia Inc., RI, USA) FEA package was then used to develop the mesh structure for the model. The mesh density and geometry was defined to represent the anatomical features of the actual segment including the cortical and cancellous bone layers, cartilaginous structures, facet joints, and ligaments. Hexagonal 3D elements were used to represent the bony structure as well as the intervertebral disc components. The facet joints were simulated using the Gap elements (GAPUNI) within the Abaqus software. These elements transfer compression force between nodes along a single direction as the gap is closed. The disc annulus was simulated as a composite structure including a solid matrix with embedded fibers in concentric rings. The fibrosis layers in the disc were simulated using the REBAR option with no-compression behavior and the fiber orientation at $30^{\circ}$ to the horizontal in alternating layers. The fiber thickness and stiffness increased in the radial direction. The nucleus pulposus was modeled with 3D incompressible fluid continuum elements. The cartilagenous endplate was not simulated in this model due to the fact that degenerative disc patients typically have little to no cartilagenous endplate left. All of the seven major ligaments, including the interspinous, supraspinous, intertransverse, posterior longitudinal, capsular, anterior longitudinal, and ligamentum flavum were simulated as truss elements. A nonlinear material definition was used to simulate appropriate material behavior of these ligaments. This nonlinear material formulation allows simulation of naturally changing ligament stiffness (initially low stiffness at low strains followed by increasing stiffness at higher strains). The material properties for various spinal elements are presented in Table 1 and a 3D rendering of the L4-L5 model is shown in Figure 2.

The FE model was modified to simulate the PLIF surgical procedure for the placement of the interbody devices. Accordingly, the simulation involved bilateral medial facetectomies, partial removal of laminae, and incision of ligament flavum and posterior longitudinal ligaments. Additionally, the elements corresponding to the nucleus pulposis component of the model were also removed and annulus windows were cut in the postero-lateral region of the model for the placement of the interbody devices.
The 3D geometries of both VariLift-L and BAK interbody devices were made and then meshed using tetragonal continuum elements. Material properties of VariLift-L and BAK fixation devices were defined using associated Young's Modulus (E) and Poisson's ratio (v) for the titanium $(\mathrm{Ti})(\mathrm{E}=115 \mathrm{GPa}, \mathrm{v}=0.34)$ [8]. The BAK device was seated on cancellous bone $(\mathrm{E}=100 \mathrm{MPa}, \mathrm{v}=0.2)$ due to the reaming to create a channel to implant, whereas the VariLift-L was threaded into the annulus space without disrupting the cortical bone of the endplate

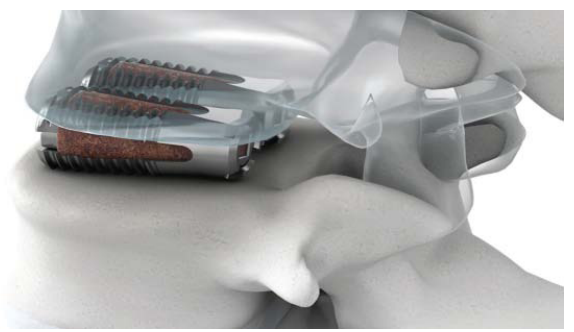

Figure 1: VariLift-L expandable lumbar interbody fusion device (Wenzel Spine, Austin, TX).

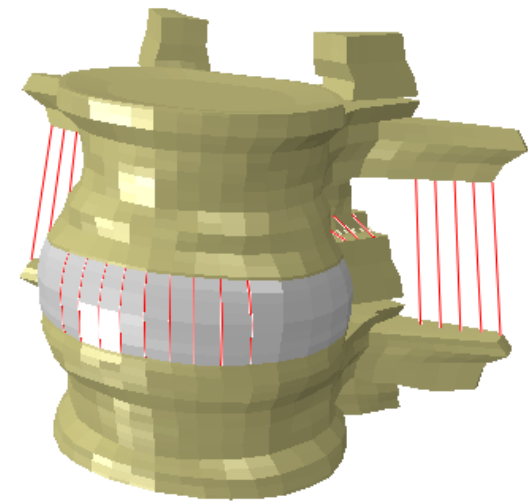

Figure 2: Finite element model of intact ligamentous L4-L5 FSU extracted from our previously published L3-S1 FE model [17-19].
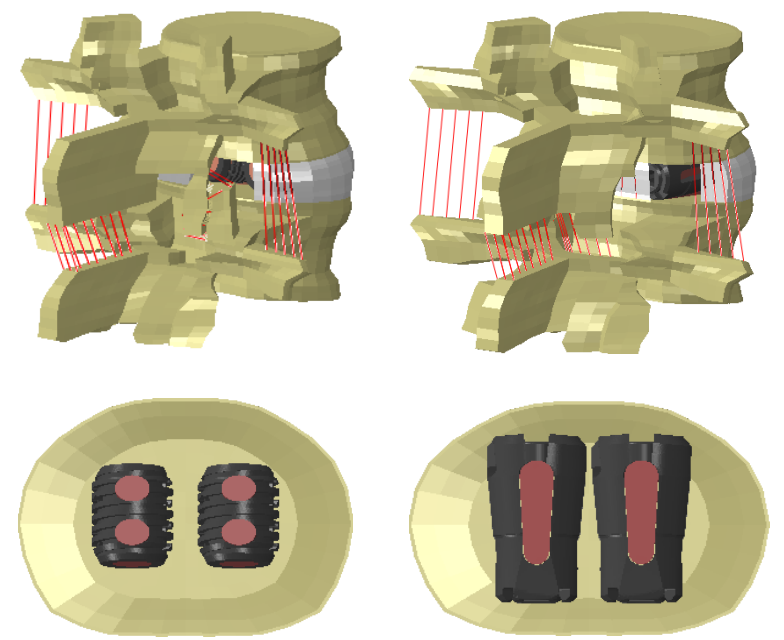

Figure 3: Top row: Finite element model of FSU implanted with BAK cage (left) and with VariLift-L device (right) Bottom row: Placement of interbody devices with respect to the endplate: BAK (right), VariLift $-L$ (right). The bone graft was simulated within the cages. 
Citation: Kiapour A, Kiapour AM, Kodigudla M, Hill GM, Mishra S, et al. (2012) A Biomechanical Finite Element Study of Subsidence and Migration Tendencies in Stand-Alone Fusion Procedures - Comparison of an In Situ Expandable Device with a Rigid Device. J Spine 1:120. doi:10.4172/2165-7939.1000120

Page 3 of 5

\begin{tabular}{|c|c|c|c|}
\hline Component & Element Formulation & Modulus (MPa) & Poisson's Ratio \\
\hline \multicolumn{4}{|l|}{ Bony Structures } \\
\hline Vertebral Cortical Bone & Isotropic, elastic hex elements & 12,000 & 0.3 \\
\hline Vertebral Cancellous Bone & Isotropic, elastic hex elements & 100 & 0.2 \\
\hline Posterior Cortical Bone & Isotropic, elastic hex elements & 12,000 & 0.3 \\
\hline Posterior Cancellous Bone & Isotropic, elastic hex elements & 100 & 0.2 \\
\hline \multicolumn{4}{|l|}{ Intervertebral Disc } \\
\hline Annulus (ground) & Neo Hookian, hex elements & $C 10=0.348, D 1=0.3$ & \\
\hline Annulus (fiber) & Rebar & $357-550$ & 0.3 \\
\hline Nucleus Pulposus & Incompressible fluid, cavity elements & 1 & 0.499 \\
\hline \multicolumn{4}{|l|}{ Ligaments } \\
\hline Anterior Longitudinal & Tension-only, Truss elements & $7.8(<12 \%), 20.0(>12 \%)$ & 0.3 \\
\hline Posterior Longitudinal & Tension-only, Truss elements & $10.0(<11 \%), 20.0(>11 \%)$ & 0.3 \\
\hline LigamentumFlavum & Tension-only, Truss elements & $15.0(<6.2 \%), 19.5(>6.2 \%)$ & 0.3 \\
\hline Intertransverse & Tension-only, Truss elements & $10.0(<18 \%), 58.7(>18 \%)$ & 0.3 \\
\hline Interspinous & Tension-only, Truss elements & $10.0(<14 \%), 11.6(>14 \%)$ & 0.3 \\
\hline Supraspinous & Tension-only, Truss elements & $8.0(<20 \%), 15.0(>20 \%)$ & \\
\hline Capsular & Tension-only, Truss elements & $7.5(<25 \%), 32.9(>25 \%)$ & 0.3 \\
\hline \multicolumn{4}{|l|}{ Joint } \\
\hline Apophyseal Joints & Non-linear Soft contact, GAPPUNI elements & --- & --- \\
\hline
\end{tabular}

Table 1: Material properties assigned to spinal components of the FE model [10].

$(\mathrm{E}=1200 \mathrm{MPa}, \mathrm{v}=0.3)$. The devices were filled with cancellous bone as shown in Figure 3.

The translation of an interior sliding plate expands the device, allowing the surgeon to control the lordotic angle between the opposing endplates. This behavior was simulated using a frictionless contact formulation between the interior expansion plate and the device wedges. Once the devices were fully expanded, the contact behavior was changed to 'rough contact,' simulating the rigid bonding between the device and the endplate.

Each model was the subjected to a $400 \mathrm{~N}$ compressive follower pre-load and an $8 \mathrm{Nm}$ bending moment to simulate physiological loadings of flexion (Flex), extension (Ext), left bending (LB), and left rotation (LR). Range of motion, shear force, and stress distribution at the device-endplate interfaces were computed and compared among models.

\section{Results}

In extension, the VariLift-L expandable device resulted in more reduction in motion ( $47 \%$ of intact spine) compared to the BAK (54\% of intact spine) stand-alone cage construct, as shown in Figure 4. Similar effects were observed in flexion (33\% of intact spine) and axial rotation ( $12 \%$ of intact spine) loadings. In lateral bending, the BAK and VariLift-L models had similar reductions in motion (21\% of intact spine).

The normal loads on the L5 endplate are presented in Figure 5. In all loading modes for the stand-alone models, the loads for the VariLift-L device were similar to those of the BAK cage (both devices are fabricated from titanium alloy). The VariLift-L device demonstrated higher shear loads as compared to the BAK cage as shown in Figure 6.

\section{Discussion}

Numerous simulations have evaluated the biomechanical effects of different Interbody fusion systems on the lumbar spine. From a biomechanical perspective, subsidence and migration of the device can interfere with bone fusion with the vertebral bodies [20-24]. Understanding the changes in kinematics and load sharing at the device/endplate interface following placement of the interbody devices are crucial as they can provide insight into the long term performance of the procedure and predict the risk for adverse effects. FE analysis is a helpful tool to evaluate such important biomechanical parameters as they are often impractical to measure in vitro or in vivo.

As stated earlier, the FE model has been experimentally validated using in vitro flexibility data from our lab and the literature [16,25,26]. In an in vitro study conducted in our lab, applying $8.0 \mathrm{Nm}$ of bending moments resulted in $3.1^{\circ} \pm 1.0$ (Ext), $7.1^{\circ} \pm 2.8$ (Flex), 5.0 \pm 1.8 (LB), and $2.5^{\circ} \pm 1.8$ (LR) for intact condition. Under similar loading and boundary conditions, the present $\mathrm{FE}$ model predicted range of motion close to the average (within one SD) experimental data. The predicted

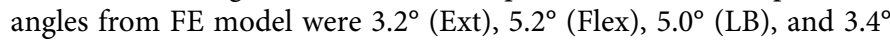
(LR) [25], demonstrating that the data presented in this paper is highly relevant.

With the exception of lateral bending, the VariLift-L expandable device was able to constrain the segmental motion in all loadings better than the BAK cage when used in a stand-alone fashion. The main reasons for unsatisfactory clinical outcomes of the stand-alone cage procedures are the increased tendency of the device to subside into the end plate, the possibility of migration into the spinal canal (A-P motion), and the lack of immediate stability of the spinal column $[8,9]$. From a biomechanical perspective, subsidence occurs due to normal loading (stress at the interface), A-P displacement (migration) occurs due to shear loading on the device, and the lack of stability occurs due to the size of the annulus cut needed to place the device within the nucleus space. The size of the annulus window for the placement of the VariLift-L device is much smaller than the BAK cage analyzed in this study because it expands in situ from a collapsed state after being placed within the disc through a smaller annulus opening.

The normal loads on the inferior endplate for the devices being compared are similar in magnitude ranging between $300 \mathrm{~N}$ to 550 $\mathrm{N}$ in different modes (Figure 5). BAK devices impacted within the endplate and seated on significantly softer bones are therefore more prone to subside due to the normal loads, as clinically observed $[13,27]$. VariLift-L has a large graft window that permits transmission of the normal loads to the bone graft in the various biomechanical modes thereby promoting fusion.

The A-P shear force in flexion on the VariLift-L device is significantly higher than the BAK in stand-alone mode (Figure 6). However, the 
Citation: Kiapour A, Kiapour AM, Kodigudla M, Hill GM, Mishra S, et al. (2012) A Biomechanical Finite Element Study of Subsidence and Migration Tendencies in Stand-Alone Fusion Procedures - Comparison of an In Situ Expandable Device with a Rigid Device. J Spine 1:120. doi:10.4172/2165-7939.1000120

Page 4 of 5

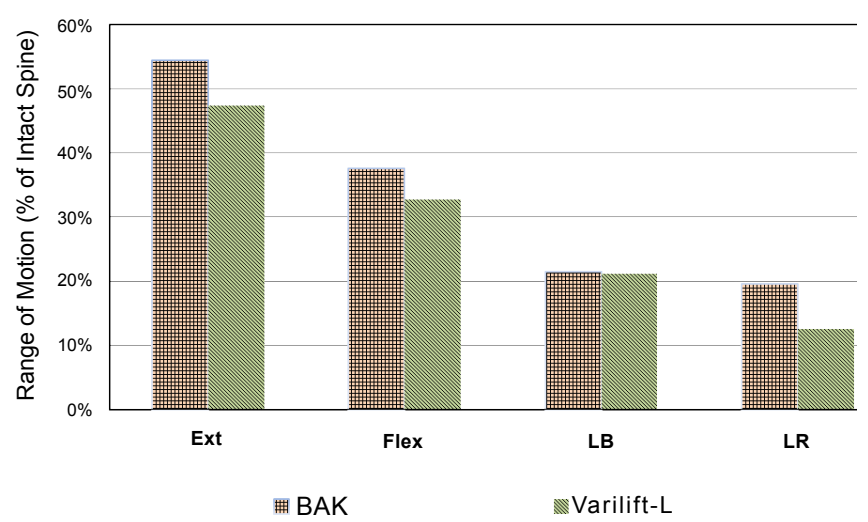

Figure 4: Percentage motion of implanted cases with respect to intact in different loadings for $400 \mathrm{~N}$ pre-load and $8.0 \mathrm{Nm}$ bending moment. A higher number represents a smaller reduction in motion with respect to the intact motion segment.

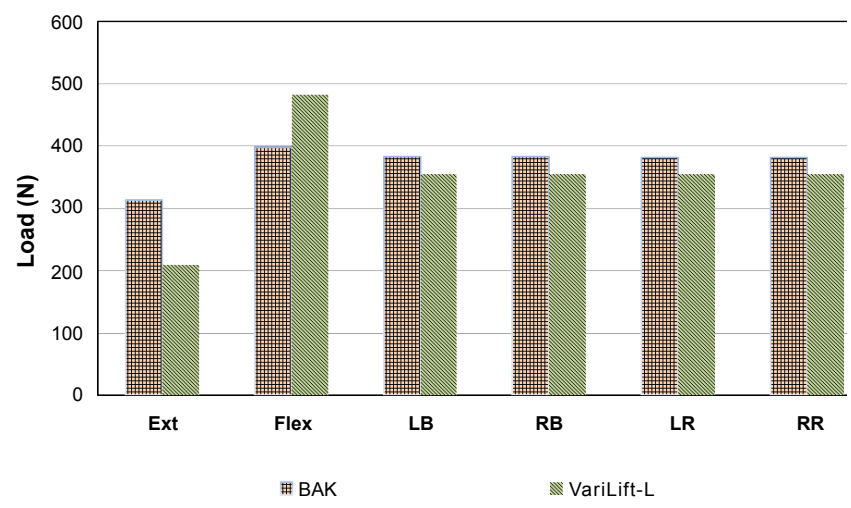

Figure 5: Normal Load on the inferior endplate of the model (L5) for different surgical cases for $400 \mathrm{~N}$ pre-load and $8 \mathrm{Nm}$ bending moment.

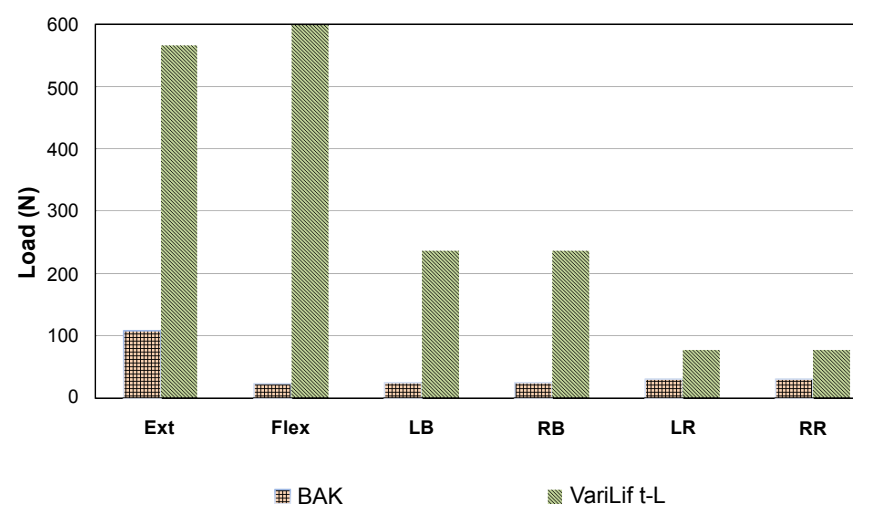

Figure 6: Shear load at the inferior of the device for different surgical cases in extension and flexion loadings for $400 \mathrm{~N}$ pre-load and $8 \mathrm{Nm}$ bending moments. In extension, shear force direction is from posterior to anterior $(P-A)$ while in flexion it is anterior to posterior (A-P).

lordotic shape of the device (bigger diameter anteriorly and smaller diameter posteriorly, in line with the lordosis curve) prevents any A-P migration under flexion. In fact, the design will have a tendency to wedge the device within the lordotic space. In extension, the shear force is in the P-A direction but the presence of the intact annulus will prevent any tendency to migrate along this direction. Another factor that prevents any migration is the depth of the groove and the grooved footprint on the endplate. VariLift-L has $48 \%$ deeper grooves and a $62 \%$ larger threaded area in contact with the endplate. In the BAK system, the device shape is cylindrical and the A-P shear force is restrained only by groove depth and softer cancellous bone in flexion which may lead to its migration, an observation in line with clinical findings [13,27]. Subsidence and migration rates for the BAK cage have been noted as $10 \%$ and $28 \%$ respectively $[13,27]$. Migration and subsidence resistance of the VariLift-L device was illustrated in a retrospective clinical review of 638 VariLift-L patients [28]. The retrospective study showed an incidence of migration in $1 \%$ of fused levels and subsidence in less than $3 \%$ of fused levels over a two year follow up. Thus, due to the VariLift-L design, the tendency for subsidence and migration is significantly lower than the traditional cylindrical device made out of the same material.

Like in vitro and in vivo studies, the computational modeling techniques have their own limitations. Inability to account for geometrical variations, material changes in tissue and anatomical variations among specimens, unlike cadaveric experiments, are few of such limitations. Also, lack of musculoskeletal structure in the model may lead to a discrepancy between the biomechanical effects observed in the FE models and the real procedure. To minimize this discrepancy, the compressive follower pre-load concept was applied to the segment and a more realistic physiological loading simulation was developed.

Finally, clinical investigations provide additional understanding of the biomechanical effects of the VariLift-L expandable device on the spinal segment and its clinical efficacy. Early term results of the aforementioned retrospective study of the VariLift-L device indicate clinical success [28]. Patient pain was reduced, on average, by $70 \%$ at 6 weeks and this reduction was maintained throughout the twoyear follow-up. Both disc height and lordosis were maintained over the follow up period. Fusion assessed by the attending surgeons and radiologists was based on visible bone growth within the device, absence of gross motion as seen on AP and lateral radiographs, and absence of radiolucent halo effects around the implant. CT scans were performed when indicated and confirmed bone growth within the devices in all patients. Based on these criteria, fusion was indicated in $99.6 \%$ of patients $(240 / 241)$ at the 24 month follow-up. The postoperative intervention rate was significantly low at $2.30 \%(6 / 260)$ at the 24 month follow-up. Literature discussing the clinical success of BAK cages reports patient pain reduction of $42 \%$ (reduction from 5.0 to 2.9 on a 6-point scale) at the 24 month time point and notes that surgical approach (PLIF or ALIF) did not significantly affect the degree of pain relief [16]. Additionally, Kuslich et al. [29] also report fusion rates for PLIF procedures utilizing BAK cages as $90.6 \%$ after 24 months. The literature states a revision surgery rate of $22 \%$ and $25 \%$ for BAK cages respectively. These clinical results are important in validation of computational efforts and also provide further insight in to the performance of the devices beyond the capabilities of FE analysis $[13,30]$. This study is significant because VariLift is the only expandable device that is cleared by FDA for standalone indication. Efforts are underway to obtain Solid Works drawings from manufacturers of other expandable devices so that additional FE analyses followed by biomechanical data comparison may be undertaken.

\section{Conclusion}

Unlike conventional interbody fixation devices, VariLift-L expandable device has the advantage of being able to adjust to the lordotic angle of the treated segment. This improves the load sharing at device-endplate interface through increasing the contact area. In addition, the trapezoid profile of the device prevents it from posterior 
Citation: Kiapour A, Kiapour AM, Kodigudla M, Hill GM, Mishra S, et al. (2012) A Biomechanical Finite Element Study of Subsidence and Migration Tendencies in Stand-Alone Fusion Procedures - Comparison of an In Situ Expandable Device with a Rigid Device. J Spine 1:120. doi:10.4172/2165-7939.1000120

Page 5 of 5

migration towards the canal and can secure the device in place to provide stability during bone fusion. Biomechanically, the VariLift-L interbody fusion device is a superior alternative compared to the traditional PLIF interbody fixation devices for fusion surgery of the lumbar spine segment.

\section{References}

1. Bhatia NN, Lee KH, Bui CN, Luna M, Wahba GM, et al. (2012) Biomechanical evaluation of an expandable cage in single-segment posterior lumbar interbody fusion. Spine (Phila Pa 1976) 37: E79-E85.

2. Folman $Y$, Lee SH, Silvera JR, Gepstein R (2003) Posterior lumbar interbody fusion for degenerative disc disease using a minimally invasive B-twin expandable spinal spacer: a multicenter study. J Spinal Disord Tech 16: 455460.

3. Goh JC, Wong HK, Thambyah A, Yu CS (2000) Influence of PLIF cage size on lumbar spine stability. Spine (Phila Pa 1976) 25: 35-39.

4. Pitzen T, Matthis D, Steudel WI (2002) The effect of posterior instrumentation following PLIF with BAK cages is most pronounced in weak bone. Acta Neurochir (Wien) $144: 121-128$

5. Schizas C, Kulik G, Kosmopoulos V (2010) Disc degeneration: current surgical options. Eur Cell Mater 20: 306-335.

6. Trouillier H, Birkenmaier C, Rauch A, Weiler C, Kauschke T, et al. (2006) Posterior lumbar interbody fusion (PLIF) with cages and local bone graft in the treatment of spinal stenosis. Acta Orthop Belg 72: 460-466.

7. Vadapalli S, Robon M, Biyani A, Sairyo K, Khandha A, et al. (2006) Effect of lumbar interbody cage geometry on construct stability: a cadaveric study. Spine (Phila Pa 1976) 31: 2189-2194.

8. Vadapalli S, Sairyo K, Goel VK, Robon M, Biyani A et al (2011) Biomechanica rationale for using polyetheretherketone (PEEK) spacers for lumbar interbody fusion-A finite element study. Spine (Phila Pa 1976) 31: E992-E998.

9. McAfee PC, Cunningham BW, Lee GA, Orbegoso CM, Haggerty CJ, et al (1999) Revision strategies for salvaging or improving failed cylindrical cages. Spine (Phila Pa 1976) 24: 2147-2153.

10. Sorensen JR, Koroma KE, Ding M, Wendt D, Jespersen S, et al. (2012) Effects of a perfusion bioreactor activated novel bone substitute in spine fusion in sheep. Eur Spine J.

11. Zdeblick TA, Phillips FM (2003) Interbody cage devices. Spine (Phila Pa 1976) 28: S2-S7.

12. Choi JY, Sung KH (2012) Subsidence after anterior lumbar interbody fusion using paired stand-alone rectangular cages. Eur Spine J 15:16-22.

13. Chen L, Yang H, Tang T (2012) Cage migration in spondylolisthesis treated with posterior lumbar interbody fusion using BAK cages. Spine (Phila Pa 1976) 30: 2171-2175.

14. Aoki Y, Yamagata M, Nakajima F, Ikeda Y, Takahashi K (2009) Posterio migration of fusion cages in degenerative lumbar disease treated with transforaminal lumbar interbody fusion: a report of three patients. Spine (Phila Pa 1976) 34: E54-E58.
15. Uzi EA, Dabby D, Tolessa E, Finkelstein JA (2001) Early retropulsion of titanium-threaded cages after posterior lumbar interbody fusion: a report of two cases. Spine (Phila Pa 1976) 26: 1073-1075.

16. Jou YC, Tsai YS, Hsieh HY, Chen SY, Tsai HT, et al. (2005) Plasma thymosin- $\alpha 1$ level as a potential biomarker in urothelial and renal cell carcinoma. Urol Oncol.

17. Grauer JN, Biyani A, Faizan A, Kiapour A, Sairyo K, et al. (2006) Biomechanics of two-level Charite artificial disc placement in comparison to fusion plus singlelevel disc placement combination. Spine J 6: 659-666.

18. Ivanov AA, Kiapour A, Ebraheim NA, Goel V (2009) Lumbar fusion leads to increases in angular motion and stress across sacroiliac joint: a finite element study. Spine (Phila Pa 1976) 34: E162-E169.

19. Sairyo K, Sakai T, Yasui N, Kiapour A, Biyani A, et al. (2009) Newly occurred L4 spondylolysis in the lumbar spine with pre-existence L5 spondylolysis among sports players: case reports and biomechanical analysis. Arch Orthop Trauma Surg 129: 1433-1439.

20. Daffner SD, Wang JC (2010) Migrated XLIF cage: case report and discussion of surgical technique. Orthopedics 33: 518.

21. Dua K, Kepler CK, Huang RC, Marchenko A (2010) Vertebral body fracture after anterolateral instrumentation and interbody fusion in two osteoporotic patients. Spine J 10: e11-e15.

22. Mehta AI, Mohrhaus CA, Husain AM, Karikari IO, Hughes B, et al. (2012) Dorsa column mapping for intramedullary spinal cord tumor resection decreases dorsal column dysfunction. J Spinal Disord Tech 25: 205-209.

23. Oliveira L, Marchi L, Coutinho E, Pimenta $L$ (2010) A radiographic assessment of the ability of the extreme lateral interbody fusion procedure to indirectly decompress the neural elements. Spine (Phila Pa 1976) 35: S331-S337.

24. Papanastassiou ID, Eleraky M, Vrionis FD (2011) Contralateral femoral nerve compression: An unrecognized complication after extreme lateral interbody fusion (XLIF). J Clin Neurosci 18: 149-151.

25. Kiapour A, Serhan H, Goel V (2012) Biomechanics of Interbody Lateral Cage and Plate vs. lateral cage and Posterior Screw Fixation.

26. Kiapour A, Ambati D, Hoy RW, Goel VK (2012) Effect of graded facetectomy on biomechanics of Dynesys dynamic stabilization system. Spine (Phila Pa 1976) 37: E581-E589.

27. Beutler WJ, Peppelman WC Jr. (2003) Anterior lumbar fusion with paired BAK standard and paired BAK Proximity cages: subsidence incidence, subsidence factors, and clinical outcome. Spine J 3: 289-293.

28. Neely W, Fitchel F, Kingman T, Cardenas del Monaco D, Hill GM, et al. (2012 A Retrospective Clinical Evaluation of Stand-Alone Posterior Lumbar Interbody Fusion using an Expandable Device for the Treatment of Single or Multi-Leve Disc Herniation with Instability and/or Degenerative Disc Disease

29. Kuslich SD, Ulstrom CL, Griffith SL, Ahern JW, Dowdle JD (1998) The Bagby and Kuslich method of lumbar interbody fusion. History, techniques, and 2-year follow-up results of a United States prospective, multicenter trial. Spine (Phila Pa 1976) 23: 1267-1278.

30. Button G, Gupta M, Barrett C, Cammack P, Benson D (2005) Three- to six-year follow-up of stand-alone BAK cages implanted by a single surgeon. Spine $\mathrm{J} 5$ 155-160. 